\title{
Copper-induced damage to the hepatopancreas of the penaeid shrimp Metapenaeus dobsoni - an ultrastructural study
}

\author{
Mary K. Manisseri ${ }^{1}$, N. R. Menon ${ }^{2}$ \\ ${ }^{1}$ Central Marine Fisheries Research Institute, PB No. 1603, Kochi 682014, India \\ ${ }^{2}$ School of Marine Sciences, Cochin University of Science and Technology, Lake Side Campus, Kochi 682016, India
}

\begin{abstract}
The hepatopancreas of decapod crustaceans has been recognised as an important target organ for studying the effects of heavy metal pollution. This dynamic organ, with its capability of detoxifying heavy metals through lysosomal activities, often indicates distinct pathological disturbances. This led to the present investigation in which we examined the ultrastructure of hepatopancreas of the penaeid shrimp Metapenaeus dobsoni (Miers) exposed to culture medium containing 50 and $150 \mathrm{ppb}$ of copper. After an exposure period of $15 \mathrm{~d}$, the hepatopancreas was dissected from individuals belonging to the intermoult stage and the structure studied employing transmission electron microscopy. Structural deformities of the cells were not confined to a specific inclusion. Instead, subcellular organelles including the endoplasmic reticulum, mitochondria, basal lamina, and nucleus showed damage of varying degrees. Damage to the nucleus and its inclusions would have a profound effect on its functioning. Endoplasmic reticulum and mitochondria showed partial to total disintegration which probably would have made them non-functional. Smooth endoplasmic reticulum, the prime organelle for detoxification and lipid synthesis, also showed damage, indicating the possibility of a disruption of the cellular detoxification mechanism. Although at lower levels $(50 \mathrm{ppb})$ copper was found to induce a biphasic effect on the histology and histochemistry of the hepatopancreas, this was not reflected in the nature of structural damage of the subcellular organelles performing vital functions. Presence of electron-dense granules in the haemolymph and epithelial cells is indicative of the role played by these granules in detoxification or demobilisation of copper.
\end{abstract}

KEY WORDS: Copper-induced damage - Hepatopancreas - Metapenaeus dobsoni

\section{INTRODUCTION}

Cellular assay techniques are employed to study pollutant-induced injuries on the internal organ systems of organisms. Such injuries serve as reliable biological indicators of pollution and are effectively used in assessing stress effects. The crustacean hepatopancreas displays considerable cytological, cytochemical and ultrastructural alterations at chronic exposure to low levels of heavy metals. Hence, it has been identified as a target organ of interest in toxicity investigations. Ultrastructural studies aid in locating the specific cell types in different organs which constitute targets. Such studies thus answer questions concerning specific alterations at the cellular level.
Crustaceans play a significant role in marine food chains. They also form a group of animals which are frequently sensitive to heavy metals. With the exception of mercury and silver, copper is the most toxic metal to marine organisms (Bryan 1976). The pathways of entry of copper into the body of crustaceans, the organs or organelles where accumulation takes place and the processes by which the metal gets sequestered and when possible eliminated from the body have been the subject of much investigation over the past 3 decades (Kerkut et al. 1961, Miyawaki et al. 1961, Gibson \& Barker 1979, White \& Rainbow 1986, Arumugam \& Ravindranath 1987). Structural compartmentation of copper in membrane-limited vesicles has been reported in Carcinus maenas (Chassard- 
Bouchard 1982), Oniscus asellus (Marcaillou et al. 1986) and Penaeus semisulatus (Al-Mohanna \& Nott 1987). In a study on accumulation and toxicity of copper in Penaeus orientalis, Liu Fayi et al. (1988) reported maximum accumulation of copper in hepatopancreas.

Xenobiotic-induced sublethal cellular pathology reflects perturbations of function and structure at the molecular level. Earlier detectable changes are associated with subcellular organelles such as the mitochondria, lysosomes or endoplasmic reticulum (Moore 1985). The interaction of heavy metals with nuclear proteins and ribosomes, and their possible mutagenic effects, have been documented by Viarengo et al. (1982) and Viarengo (1985). Conney \& Burns (1972), Buiss \& Gibson (1979) and Livinysione (1985) studied the deleterious effects of xenobiotics on the membranes of endoplasmic reticulum.

In the present study, the ultrastructural alterations brought about by copper toxicity in the hepatopancreas of a commercially important penaeid prawn Metapenaeus dobsoni (Miers) have been elucidated. The rationale arose out of the concept that the cells and cell organelles of the hepatopancreas might depict alterations or damage which could be associated with stress at organismic or organic levels.

\section{MATERIALS AND METHODS}

Juvenile Metapenaeus dobsoni (measuring 25 to $35 \mathrm{~mm}$ from the tip of the rostrum to the tip of the telson) collected from prawn culture fields at Vypeen $\left(76^{\circ} 10^{\prime} \mathrm{E}, 10^{\circ} 00^{\prime} \mathrm{N}\right)$ were acclimatized to a salinity of $20 \pm 2$ ppt. The medium was well-aerated and the shrimp were fed ad libitum on fresh clam meat. Copper sulphate was used as the source of heavy metal. Ten shrimp each were exposed to 50 and $150 \mathrm{ppb}$ of copper in a semi flow-through system for $15 \mathrm{~d}$ at room temperature $\left(28 \pm 2^{\circ} \mathrm{C}\right)$. Test solutions were prepared from a stock solution and $2 / 3$ of the test solution in each tub was replenished every $24 \mathrm{~h}$. A control was also run along with the treatments, in which the shrimp were kept in filtered seawater, which also was changed every $24 \mathrm{~h}$. Left-over feed, faecal matter and exuvia were siphoned out every $24 \mathrm{~h}$.

The hepatopancreatic tissue of Metapenaeus dobsoni individuals in the intermoult stage was examined employing electron microscopy. The tissues were obtained from 3 individuals from each treatment, sacrificed at the end of the experiment. Hepatopancreas was dissected out and fixed immediately in cold $\left(4^{\circ} \mathrm{C}\right)$ cacodylate-buffered glutaraldehyde solution $(5 \%)$ at $\mathrm{pH} 7.2$ for $12 \mathrm{~h}$. The tissue was then washed 3 times in cacodylate buffer, trimmed and washed again in fresh buffer solution. Next the samples were fixed in $1 \%$ osmium tetroxide at $4^{\circ} \mathrm{C}$ for $2 \mathrm{~h}$. Osmium tetroxide was then drained out and the tissue was washed in fresh buffer solution several times, followed by washing in double-distilled water. Dehydration of the tissue was done in ascending series of ethanol concentrations (15 min each in 30\%, 50\%, 70\%, 90\% and absolute) at $4^{\circ} \mathrm{C}$, giving 2 washes at each step. Different concentrations of ethanol and Spurr's resin without DMAE $(75: 25,50: 50,25: 75)$ were used for infiltration. Finally, the tissue was embedded in Spurr's embedding resin, keeping the moulds at $70^{\circ} \mathrm{C}$ for $24 \mathrm{~h}$.

Silver-coloured ultra thin sections were taken with an 'Ultracut E' (LKB) ultramicrotome; sections were mounted on copper grids and stained with uranyl aceiate (vivatson i9̄ô) and lead cltrate (Reynolds 1963). The sections were examined and electron micrographs were taken in a Philips EM 300 transmission electron microscope, operating at $60 \mathrm{kV}$.

For light microscopy, the tissues were fixed in Bouin's fixative, dehydrated using ethyl alcohol, cleared in xylene and embedded in paraffin wax $\left(58\right.$ to $\left.60^{\circ} \mathrm{C}\right)$. Sections of $7 \mu \mathrm{m}$ thickness were obtained, stained in Delafield's haematoxylin and eosin and mounted in DPX (Dextrene Plasticizon Xylene), following standard methodology.

\section{RESULTS}

We analysed the fine structure of Metapenaeus dobsoni hepatopancreas both with and without exposure to copper. Fig. 1a, b (light micrographs) presents the different cell types of the hepatopancreas of shrimp maintained under control conditions. Electron micrographs (Fig. 2a, b) depict the fine structure of the $\mathrm{R}$ - and F-cells of normal hepatopancreas. Cytoplasm of the cell is traversed with endoplasmic reticulum with uniformly arranged ribosomes. Primary lysosomes containing electron-dense inclusions and mitochondria of varying sizes are found in the cytoplasm. A distinct basal lamina separates the haemolymph space from the cell. Clumps of chromatin are found dispersed at the center and along the periphery of the nucleus. The B-cells contain vacoules with inclusions which are generally found to be uniformly distributed, forming homogeneous bodies.

The hepatopancreas of prawns exposed to $50 \mathrm{ppb}$ of copper showed structural damage to the cells. The variations found in the ultrastructure of cells included damaged nuclei, disfigured and disintegrated endoplasmic reticulum, and excessive accumulation of glycogen in the endoplasmic reticulum. The mitochondrial membrane was distended in some locations and partially degenerated in others (Fig. 3). Numerous electron-dense 

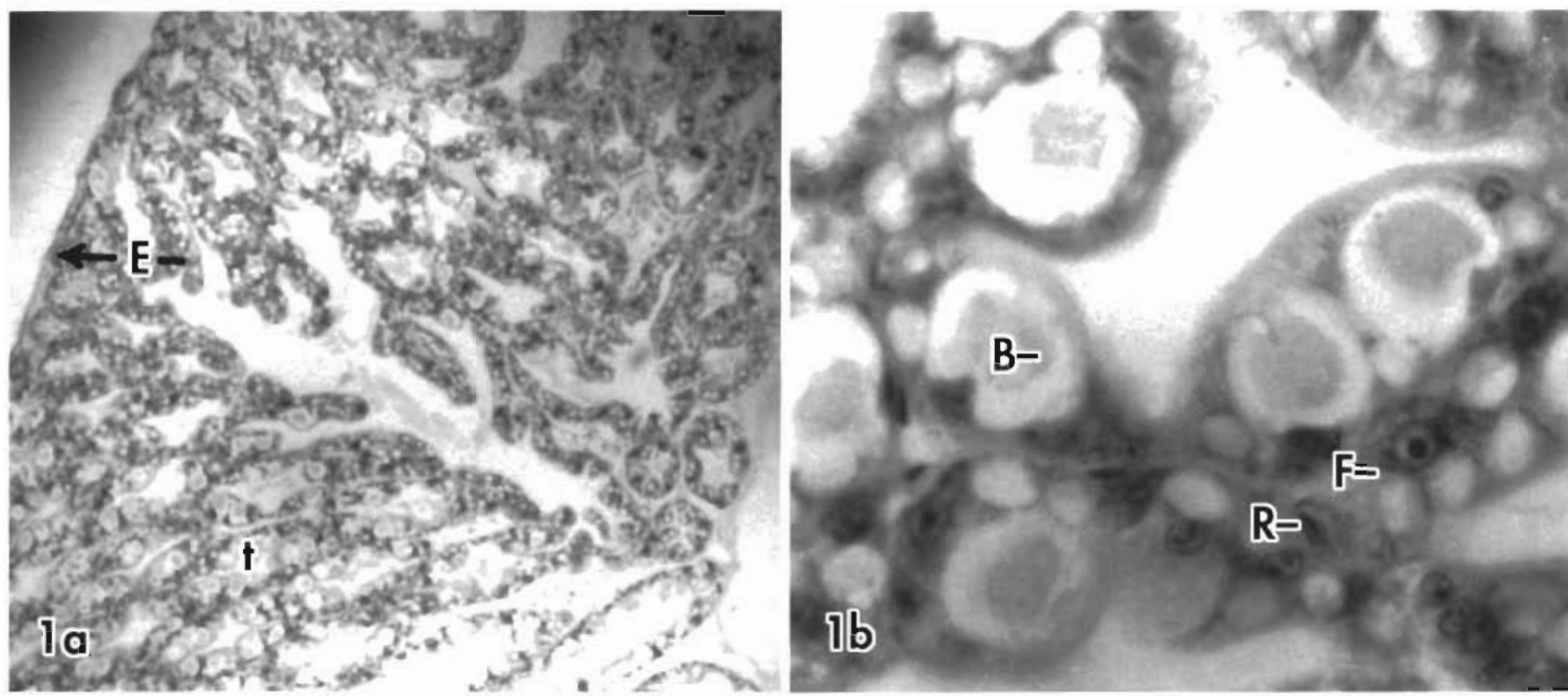

Fig. 1. Metapenaeus dobsoni. Cross section of hepatopancreas of shrimp maintained under controlled conditions showing tubules (t) and different cell types (E-, R-, F-and B-). Light microscopy; (a) $\times 20$, (b) $\times 200$

bodies, distributed near the inner side of the basal lamina, appeared to be inclusions into which copper has been incorporated (Fig. 4). In one instance, a large electron-dense area was identified inside the haemolymph space. We believe that this was a copper-rich inclusion being transported into the cell through the basal lamina. Totally disarrayed lipid droplets were distributed inside the cells. The microvilli of the cells did not display any structural deformity.

In the case of the hepatopancreas of Metapenaeus dobsoni exposed to $150 \mathrm{ppb}$ of copper, almost all the car- dinal inclusions of the cell were destroyed to various degrees. Many nuclei had lost their typical elliptical shape due to extensive shrinkage of the nuclear membrane (Fig. 5). This resulted in denser distribution of chromatin. An enlarged view of the nucleus showed characteristic ruffling of the nuclear membrane. The shrinkage could be due either to disruption of the tensile strength of the nuclear membrane or to dehydration of the nuclear content. The rough endoplasmic reticula lacked their characteristic arrangement. They were broken down into very minute pieces (ca $8 \mathrm{pm}$ ) and were dis-
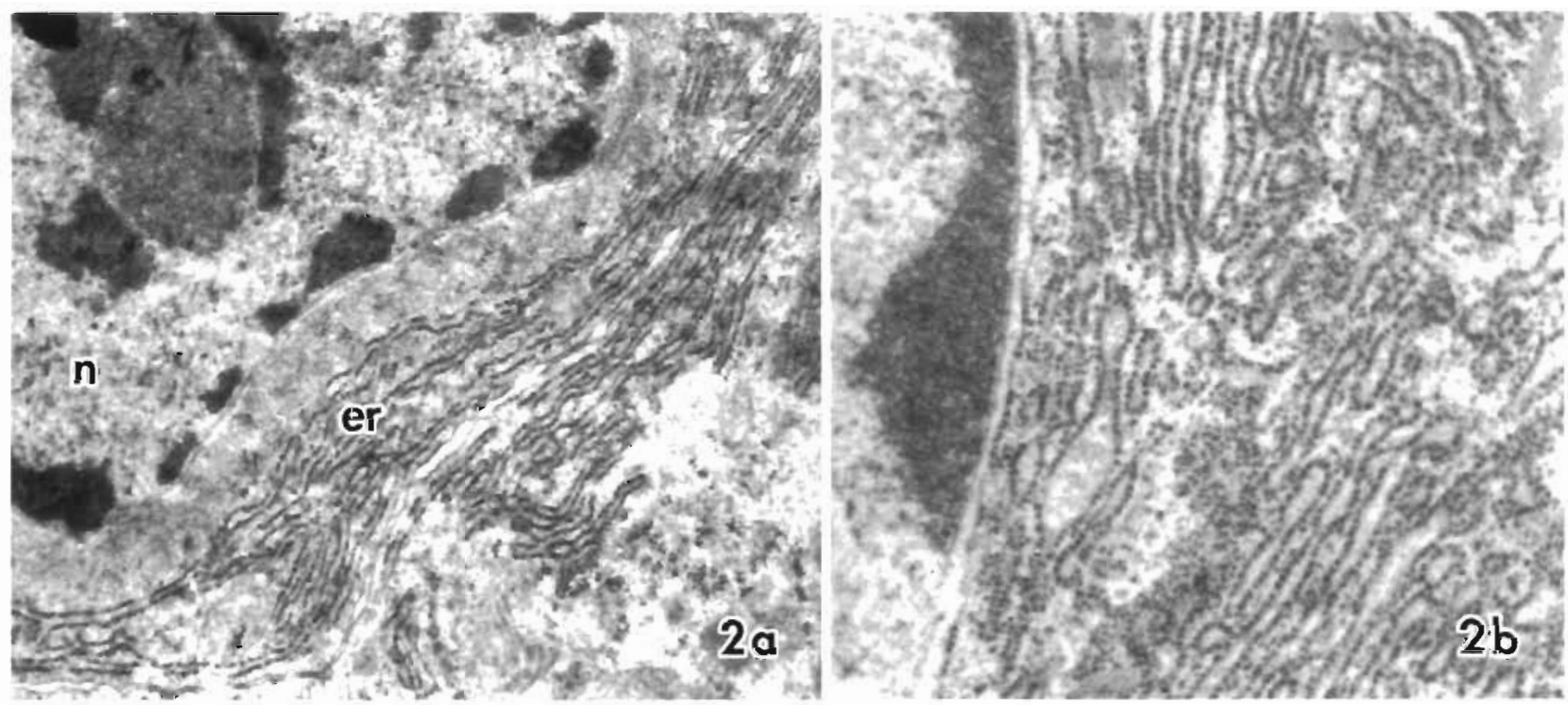

Fig. 2. Metapenaeus dobsoni. Ultrastructure of normal R- and F-cells of the hepatopancreas of shrimp maintained under control conditions. (a) $\times 16200$; n: nucleus; er: endoplasmic reticulum; (b) $\times 25700$ 


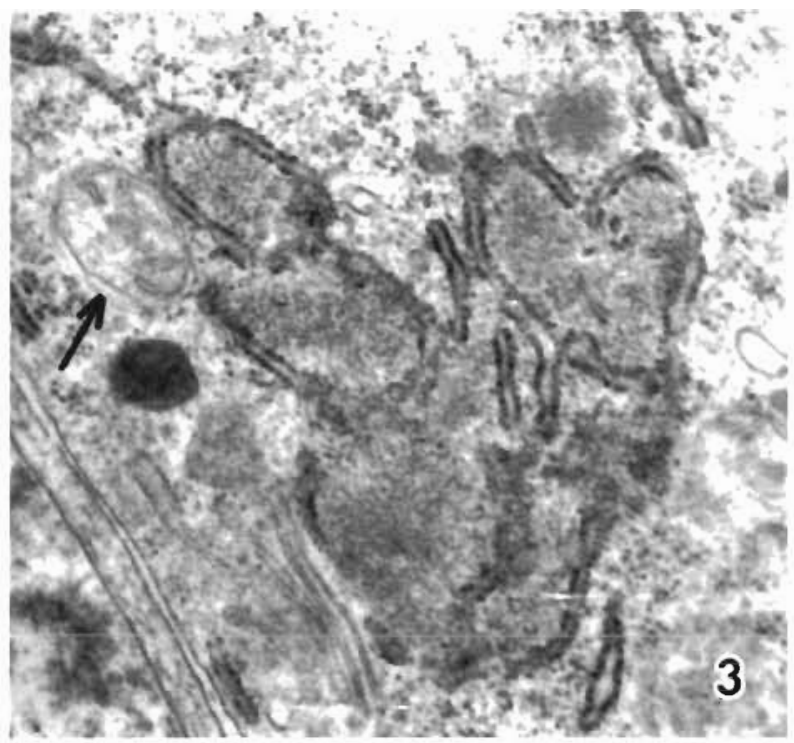

Fig. 3. Metapenaeus dobsoni. Ultrastructure of the R-cell of the hepatopancreas of shrimp showing swollen mitochondria when exposed to $50 \mathrm{ppb}$ copper. $\times 25700$

tributed haphazardly throughout the cells (Fig. 6). Mitochondria were also found to lose their characteristic shape. In a few instances, mitochondria were found totally disintegrated in the R-cells (Fig. 6). The basal lamina had developed characteristic foldings and the folds were found to contain electron-dense material which could have been copper-rich inclusions (Fig. 7); these may possibly be 'nipped off' and taken onto the cell. thereby resulting in transfer of copper from the haemolymph to the cell.

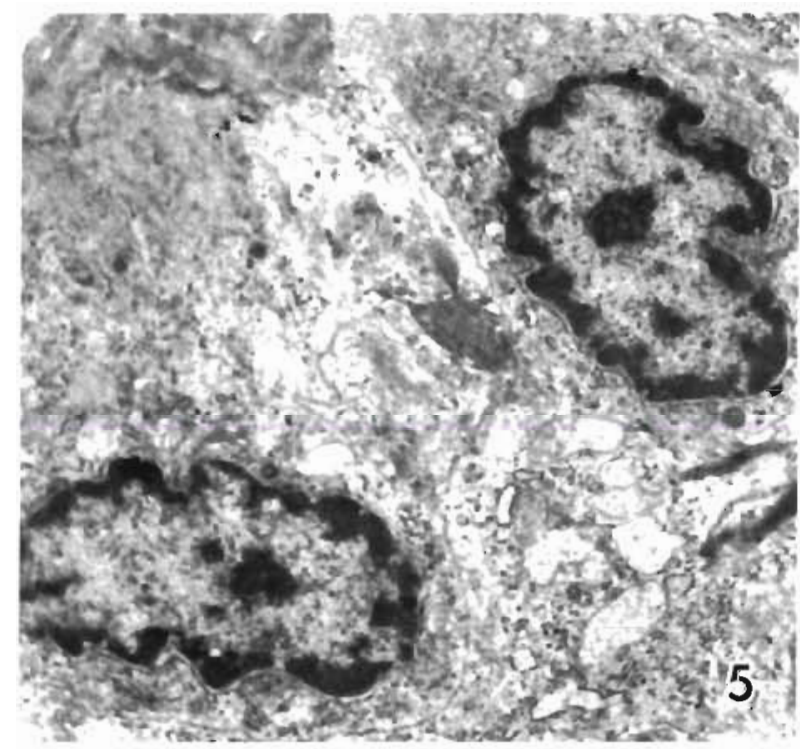

Fig. 5. Metapenaeus dobsoni. Distorted nuclei in the hepatopancreatic cells of shrimp exposed to $150 \mathrm{ppb}$ of copper. $\times 7300$

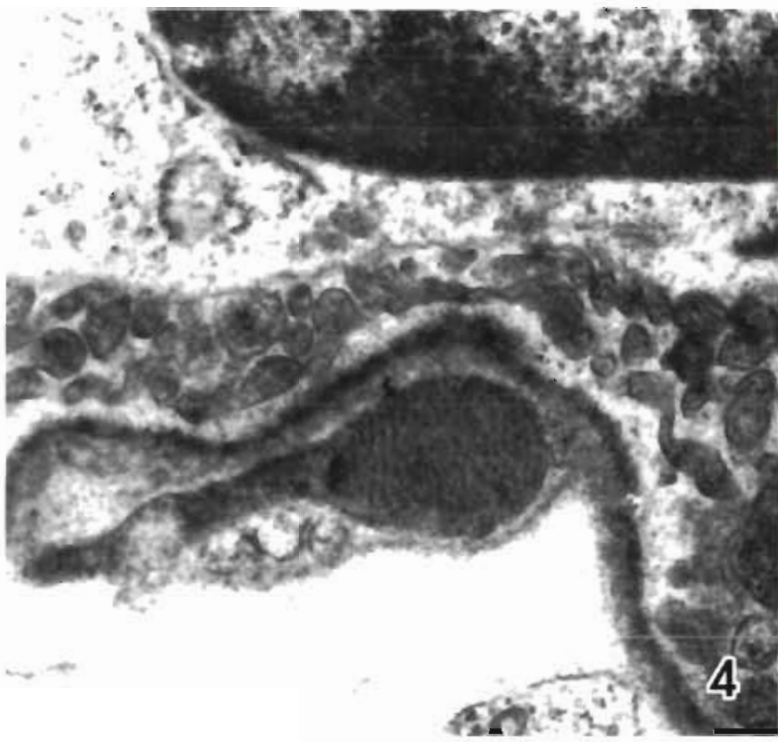

Fig. 4. Metapenaeus dobsoni. Ultrastructure of the hepatopancreas of shrimp exposed to $50 \mathrm{ppb}$, copper showing electron-dense bodies near the basal lamina of R-cells. $\times 25700$

\section{DISCUSSION}

Heavy metals at sublethal levels are known to affect the structure and functioning of cellular components, leading to impairment of vital functions of many marine organisms. It is in this context that histopathological and ultrastructral alterations are employed as effective indices of physiological and biochemical changes caused by copper-induced stress. These biological indices provide insight into cellular injuries

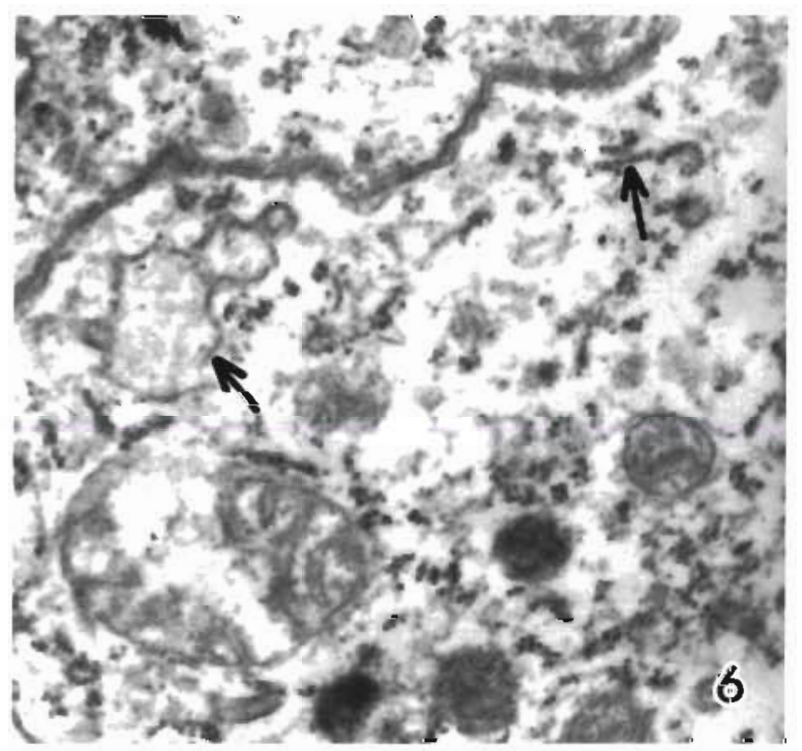

Fig. 6. Metapenaeus dobsoni. Degeneratıng endoplasmic reticulum and mitochondria in R-cell of the hepatopancreas of shrimp exposed to 150 ppb copper. $\times 25700$ 


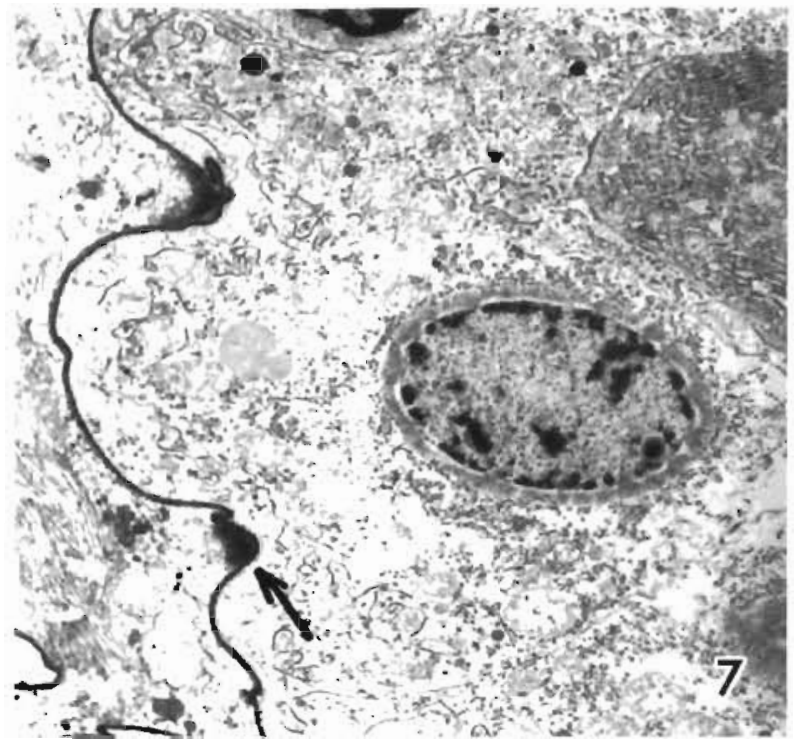

Fig. 7. Metapenaeus dobsoni. R-cell with folded basal lamina containing electron-dense material in the hepatopancreas of shrimp exposed to 150 ppb copper. $\times 4800$

before any irreversible alteration occurs. The hepatopancreas is a vital organ in crustaceans, with secretory, absorptive, digestive and excretory functions. This organ has been identified as a target organ for heavy metal pollution because it shows critical histopathological and ultrastructural alterations at very early stages of exposure to toxicants. The present study on copper-exposed Metapenaeus dobsoni elucidates the major ultrastructural alterations brought about in the vital organelles of hepatopancreas cells.

Most of the authors who have studied the hepatopancreas of crustaceans have agreed on a classification of the epithelial cells into 4 groups (E-, R-, F- and B-cells) and that they are formed by a sequence of cellular differentiation (e.g. Gibson \& Barker 1979, Hopkin \& Nott 1980, Dall \& Moriarty 1983). In the present study, the structural details of various cellular components of the hepatopancreas in control prawns confirmed with the descriptions given in the literature. The hepatopancreas cells of Metapenaeus dobsoni exposed to the low copper level harboured damaged cardinal organelles such as mitochondria, endoplasmic reticulum and nuclear membrane. The nuclear damage observed included distortion of nuclei with 'scalloped' edges, damage of the nuclear membrane, and overall shrinkage resulting in the nuclei losing their characteristic shape. These changes would profoundly influence the normal functioning of the nuclei. Metals can interact with nuclear proteins, altering the complex structure of chromatin or the catalytic activity of the enzymes involved in DNA and RNA metabolism (Viarengo 1985). Metal cations can also induce depoly- merisation and favour hydrolysis of RNA, affect the correct replication or transcription of DNA, and alter the fidelity of the translation of RNAs during the process of protein synthesis at the ribosomal level.

Extensive disruption and disintegration of the endoplasmic reticulum observed in the prawns exposed to copper may indicate serious deleterious alterations associated with heavy metal stress. The extent of damage seemed to be directly proportional to the concentration of toxicant in the medium. Detoxification and lipid synthesis are among the special functions of smooth endoplasmic reticulum (De Robertis \& De Robertis 1980). Copper reduces the rate of protein synthesis by reducing the rate of RNA synthesis, influencing the attachment of polyribosomes to the rough endoplasmic reticulum, and potentially damaging the ribosomes themselves (Viarengo 1985). A general negative effect exerted by metals on the membranes of both the rough and smooth endoplasmic reticulum is due to lipid peroxidation (Buss \& Gibson 1979). Structural damage of the kind noticed in the mitochondria of Metapenaeus dobsoni exposed to copper would probably render this organelle less or non-functional. Since various enzymes which participate in the formation and transfer of high energy phosphate bonds are located in the mitochondria, the role of mitochondria appears to be the formation and liberation of compounds of high phosphate transfer potential (e.g. ATP). Injury to mitochondria may produce degenerative changes consisting of fragmentation and intense swelling (De Robertis \& De Robertis 1980).

Increased accumulation of residual glycogen enmeshed in the endoplasmic reticulum and the appearance of disarrayed lipid droplets in the prawns exposed to $50 \mathrm{ppb}$ of copper probably indicate a biphasic effect of this metal. In a study of accumulation and toxicity of copper in Penaeus orientalis, Liu Fayi et al. (1988) observed an increase in cytochrome oxidase activity in the hepatopancreas on the fourth day of the exposure period. Subsequently, a steady decrease in cytochrome activity was recorded. As cytochrome oxidase is associated with the smooth endoplasmic reticulum, this could indicate a proliferation of the latter towards the beginning of the exposure period. A biphasic effect of copper was reported in the case of Mytilus edulis by Calabrese et al. (1984). Moore (1988) also reported a biphasic effect of a mixture of diesel oil and copper in molluscan digestive cells. Accumulation of large quantities of lipid droplets has been observed in Metapenaeus dobsoni exposed to copper. Similar observations have been made by Lowe (1988) and Moore (1988) in the case of mussels exposed to toxic substances.

Metapenaeus dobsoni exposed to copper showed merging of vesicles or vacuoles containing electron- 
dense materials. The inclusions were not uniformly spaced as in the control prawns. The lysosomalvacuolar systems is considered to be the major degradative system within the cell. Tertiary lysosomes in the hepatopancreas and excretory organs can accumulate large quantities of metals. Many invertebrates including crustaceans are to excrete these bodies by a process of exocytosis (George 1982). Numerous electron-dense inclusions seen near the basal lamina of hepatopancreas cells of copper-exposed $M$. dobsoni could be metal-rich bodies in the process of being transported from the heamolymph to the cell for further sequestration and elimination (Fig. 7). According to Al-Mohana \& Nott (1987), the R-cells in the hepatopancreas of Penaeus semisulcatus can take up particuiate materiai irom the haemolymph by pinocytosis at the basal cell membrane. It is also reported that copper, sulphur and other elements are accumulated in large dense vacuoles. The present findings support this hypothesis.

Icely \& Nott (1980) carried out ultrastructural studies on the accumulation of copper within the hepatopancreatic caecae of the amphipod Corophium volutator. In the case of amphipods with high tissue burdens of copper, numerous granules of homogeneous electrondense material were found. Amphipods with lower tissue concentrations of copper had fewer such granules. Weeks (1992) also reported the presence of copper-rich granules containing homogeneous electron-dense material (with no nucleus or core) in the R-F-cells of the ventral caeca of Orchestia gammarellus inhabiting copper-polluted localities. The presence of electrondense granules in the haemolymph and epithelial cells of Metapenaeus dobsoni hepatopancreas indicates the role played by these granules in the detoxification and elimination of copper from the tissues of copper-contaminated individuals

Acknowledgements. This study was financed partly by the Indian Council of Agricultural Research, New Delhi.

\section{LITERATURE CITED}

Al-Mohanna SY, Nott JA (1987) R-cells and the digestive cycle in Penaeus semisulcatus. Mar Biol 95:129-137

Arumugam M. Ravindranath $\mathrm{MH}$ (1987) Copper toxicity in the crab Scylla serrata, copper levels in tissues and regulation after exposure to a copper-rich medium. Bull envlron Contam Toxicol 39:708-715

Bryan GW (1976) Heary metal contamination in the sea. In: Johnston $\mathrm{R}$ (ed) Marine pollution. Academic Press London, p 185-302

Buss JS, Gibson JE (1979) Lipid peroxidation and its role in toxicology. In: Hodgson. E, Bend JR, Philpot RM (eds) Reviews in biochemical toxicology. Elsevier, Amsterdam, p $125-149$

Calabrese A, Maclnnes JR, Nelson DA, Greig RA, Yevich PT
(1984) Effects of long-term exposure to silver or copper on growth, bioaccumulation and histopathology in the blue mussel Mytilus edulis. Mar environ Res 11:253-274

Chassard-Bouchard C (1982) Ultrastructural concentration by the digestive gland of the crab Carcinus maenas (Crustacea, Decapoda) Electron probe $x$-ray microandyzis. $\mathrm{Cr}$ hebd Seinc Acad Sci, Paris (Sér III) 294:153-158

Conney $\mathrm{AH}$, Burns JJ (1972) Metabolic interactions among environmental chemicals and drugs. Science 178:576-586

Dall W, Moriarty DJW (1983) Functional aspects of nutrition and digestion. In: Bliss DE, Mantel LH (eds) The biology of Crustacea, Vol 5, Internal anatomy and physiological regulation. Academic Press New York, p 215-251

De Robertis EDP, De Robertis EMF (1980) Cell and molecular biology, 7th edn. Holt-Saunders International Editions, Philadelphia

George SG (1982) Subcellular accumulation and detoxification of metals in aquatic animals. In: Vernberg WB, Calabrose A, Thurbcrg Fr, Vernberg ${ }^{\prime} J$ (eds) Physiological mechanisms of marine pollutant toxicity. Academic Press, New York, p 3-52

Gibson R, Barker PL (1979) The decapod hepatopancreas. Oceanogr. mar. Biol. A. Rev. 17:285-346

Hopkin SP, Nott JA (1980) Studies on the digestive cycle of the shore crab Carcinus maenas ( $\mathrm{L}$.) with special reference to the B-cells in the hepatopancreas. J mar biol Ass UK 60: $891-907$

Icely JD, Nott JA (1980) Accumulation of copper within the 'Hepatopancreatic caeca' of Corophium volutator (Crustacea: Amphipoda). Mar Biol 57:193 199

Kerkut GA, Moritz PM, Munday KA (1961) Variation of copper concentrations in Carcinus maenas. Cah Biol mar 2:399-408

Liu Fayi, Wu Yulin, Zhao Hongru, Hou Lanying, Sun Fend (1988) Accumulation and toxicity of copper in prawn Penaeus orrentalis. Oceanol Limnol Sin (Haiyang YuHuzhao) 19:133-139

Livingstone DR (1985) Responses of the detoxication/toxication enzyme systems of molluscs to organic pollutants and xenobiotics. Mar Pollut Bull 16:158 -164

Lowe DM (1988) Alterations in cellular structure of Mytilus edulis resulting from exposure to environmental contaminants under field and experimental conditions. Mar Ecol Prog Ser 46:91-100

Marcaillou C, Truchet M, Martoja TR (1986) Role of S-cells of the caecal epithelium of isopod crustaceans in the uptake and degradation of haemolymph proteins, and in the accumulation of catabolites (uric acid, copper sulphate, phosphates). Can J Zool 64:2757-2769

Miyawaki M, Matsuzaki M. Sasaki N (1961) Histochemical studies on the hepatopancreas of the cray fish Procambarus clarkiı Kumamoto, J Sci Hiroshima Univ Ser B 5: 161-169

Moore MN (1985) Cellular responses to pollutants. Mar Pollut Bull 16:134-139

Moore MN (1988) Cytochemical responses of the lysosomal system and NADPH-ferrihemoprotein reductase in molluscan digestive cells to environmental and experimental exposure to xenobiotics. Mar Ecol Prog Ser 46:81-89

Reynolds ES (1963) The use of lead citrate at high pH as an electron opaque stain in electron microscopy. J Cell Biol $17: 19-58$

Viarengo A (1985) Biochemical effects of trace metals. Mar Pollut Bull 16:153--158

Viarengo A, Pertica M, Mancinell G, Palmero S, Oruncesu M (1982) Effects of Cu on nuclear RNA polymerase activities in the mussel digestıve gland. Mar Biol Lett 3:345-352 
Watson WL (1968) Staining of tissue sections for electron microscopy with heavy metals. J biophys biochem Cytol 4 : $475-478$

Weeks JM (1992) Copper rich granules in the ventral caeca of talltrid amphipods (Crustacea: Amphipoda: Talltriae).

Responsible Subject Editor: O. Kinne, Oldendorf/Luhe, Germany
Ophelia 36:119-133

White SL, Rainbow PS (1986) A preliminary study of Cu-, Cdand $\mathrm{Zn}$-binding components in the hepatopancreas of Palaemon elegans (Crustacea: Decapoda). Comp Brochem Physiol 83C:111-116

Manuscnpt first received: Ma!y 16, 1994

Revised version accepted: January 26, 1995 